\title{
New Progress on Preschool Education Theory
}

\author{
Xueyun $\operatorname{Yan}^{1}$ \\ ${ }^{1}$ Dongchang college, Liaocheng University, Liaocheng, Shandong, 252000
}

Keywords: preschool education; theory study; application status

\begin{abstract}
Preschool education is an important part of pedagogy, which has experienced many schools in its development process. It has been ignored in the process of actual practice, but its influence on children is imperceptible. Therefore, preschool education theory studied is of great significance to children's education. The meaning of education is very broad, and there are many types of preschool education. In the course of its theoretical development, the problems of ignoring preschool education often appear repeatedly. Therefore, in the course of theoretical development of preschool education, it is necessary to analyze its current situation, reflect on emerging issues, and guide the future development of education.
\end{abstract}

\section{Introduction}

The relationship between preschool education theory and practice is a problem that has plagued preschool education researchers for many years. In the study of preschool education, we adhere to the theory we believe in. However, we often run into conflicts in practice. The attitude of first-line preschool teachers to the theory is both respectful and skeptical. Respect is because most front-line teachers believe that theory is difficult to learn, and that the theory cannot guide specific decisions, which in turn increases teachers' skepticism about the theory. This shows that there is a certain distance between the study of preschool education theory and the specific practice. Many theories are out of reach for the practice, let alone concrete guidance, which leads to the lack of foundation in the theory and the lack of guidance in practice.

\section{Anti-intellectualism, Practical Reason and Transcendence in Preschool Education Research}

In pre-school education academic circles, there are still neglected, despised and even hostile to the development of theories, especially contempt for basic theoretical research, and there is a special dislike for basic theoretical research. This aversion to theory is very harmful to the development of preschool education and the development of preschool education. This situation of aversion to theoretical research has to do with traditional Chinese production, lifestyle, and ideological traditions, so as to form a cultural unconscious mind that opposes theoretical exploration. The philosopher Ren Jiyu said in a lecture that the "small-scale peasant economy" is still affecting China at the moment, and he regards the small-scale peasant economy as a "feudal remnant". "The small-scale peasant economy can easily appreciate the benefits of the recent period. It does not look at the long-term, and the immediate interests are very important." "Another feature of the small-scale peasant economy is that it has much more direct experience. It despises the knowledge of books and considers books to be useless. In fact, the knowledge of books is The record of the previous person's direct experience. If the book knowledge is not important, just look at the direct experience, then it is narrow and very limited. The direct experience can only help you currently, it is restrictive. Change a person's experience The experience of tens of millions of people depends on indirect experience and on the popularization, dissemination, and promotion of the media. Ren Jiyue proposed to "sweep cultural blindness": "This cultural blindness is not about illiteracy but about insufficient cultural quality. The philosopher Fang Litian believes that Chinese culture is characterized by practicality and emphasis on practical issues. This is not bad, but it is "too much emphasis." After the reality, there will be some neglect of the spirit of transcendence, and the pursuit of a higher level of realm will be affected." "Should we advocate a transcendence? A higher 
level of pursuing? We believe that this is a lack of Chinese people. This is a question that needs to be explored to improve the overall quality of the nation." [5] Traditional Chinese culture emphasizes practical issues and lacks the features of metaphysical pursuit. Characteristics through the collective unconscious cultural psychology has a profound influence on the academic community of preschool education. Some scholars believe that studying preschool education is a practical issue in kindergartens, which ignores the cultural level behind the kindergartens, neglects the research on the factors behind the kindergartens, such as politics and economy, and also ignores the historical research. This neglect directly affects the discipline construction of preschool education. The anti-intellectualist argument that "theory" is useless, that theory can still be model teachers, that I don't understand "big books" and that I can still teach, is harmful to preschool education discipline construction. Academic circles have the slogan "Get out of the ivory tower," but for the preschool education discipline, there is no "ivory tower" of subject theory. What we need now is precisely the building ivory tower, and only then is it possible for people of preschool education disciplines. Full of confidence and proudly advocated "walking out of the ivory tower."

\section{Problems in the Development of Preschool Education Theory}

Due to the frequent institutional changes since ancient times, preschool education theory has also undergone great development and changes. In the pre-Qin period, China was a slave society and the social situation was relatively turbulent. Therefore, the issue of education for preschool children was rather special. Since ancient times, China has attached great importance to the theory of justice. In "Book of Rites" and "University" and "The Doctrine of the Mean", there are children growing up. Children are encouraged to enjoy the present life, and they advocate the Taoist nature education concept. However, with the replacement of social systems, children's preschool education has gradually become The ruling tools of the rulers, children's education has become a tool for the ruling class to rule, its theoretical development is not conducive to children's physical and mental health. Our country is deeply influenced by traditional culture, leading to deviations in children's educational concepts. Many education experts believe that, to this day, the awareness of the small-scale peasant economy still affects children's pre-school education theory and is not conducive to children's physical and mental growth.

Changes in society have a direct impact on the development of preschool education. In the 1960s, China's "cultural revolution" caused heavy damage to education. The development of preschool education theories is no exception. The "Cultural Revolution" thought that the emphasis on physical and mental development in children's education was a kind of "finance and repair" and was abolished. From infants to adults, all of them asked to recite Chairman Mao's quotations. Children’s ideas and perceptions of society had a huge deviation. Misconceptions and ethics.

Since the reform and opening up, international exchanges have become more frequent. There has been a fierce collision between Chinese and foreign thoughts. While absorbing the preschool education theory, China has also absorbed a lot of dross, resulting in the emergence of hedonism and egoism among many children's ideas.

\section{The Future Development Direction of Preschool Education Theory}

In the issue of preschool education theory, we should absorb the essence of traditional culture and go to the dregs, which will benefit our country's social development and the theory that is conducive to children's physical and mental health, and apply it to children's preschool education issues. Multi-level development, removing the ideology of the small-scale peasant economy, merging the concept of international education, cultivating physical and mental health, ideal children.

The research on preschool education theory in foreign countries is very in-depth, and many places are worth our country's reference. Therefore, in the study of preschool education theory, we should carry out absorptive learning according to the current state of education development in our country. For example, famous Chinese educator Chen Heqin is teaching. In the course of theoretical 
research, there is a certain amount of research on foreign education theories. Of course, in the process of carrying out preschool teaching theory research, we should pay attention to the cultural background of different education theories. We should not copy all the foreign theories, we should contact the actual development of China, carry out the theoretical refinement, look forward to the future, and conduct preschool culture. Theoretical research.

In the developmental theory of preschool education, only the result of practice is often emphasized, and the importance of academic research is neglected. Therefore, in the path of preschool education theory, theory and practice should be combined to make modern education theory conform to the education of our country. Development, focusing on children with physical and mental health.

\section{Effective Ways to Integrate Preschool Education Theory and Practice}

Preschool children mostly understand the world through their own experiences, which determines that preschool education is a typical practical educational activity. Therefore, in the pre-service training and training phase, on the basis of professional theoretical education and teaching, it is necessary to reflect and summarize the practice of early childhood education, strengthen the practicality of education and teaching, and enhance the practical value of the theory.

First, practical teaching. Practical teaching mainly includes teaching practice and teaching practice, as well as on-site teaching combined with theory.

Teaching internships or internships are the day's activities in which the students enter the kindergarten age groups and organize the children under the guidance of the class teacher. On-site teaching is mainly conducted by kindergarten teachers on-site instruction or pre-school education theory professional teachers to explain on-site. Practical teaching helps students enrich their direct experience and perceptual knowledge, visualize abstract theories, guide students to deepen and integrate theoretical knowledge, and improve students' ability to use theories to solve practical problems. Second, case teaching. Case teaching refers to "a method of guiding students to discuss these special situations through the description of specific educational situations". [5] The use of case studies and other teaching methods in theoretical teaching can effectively compensate for the shortcomings of practical teaching by simulating and reproducing the real scenes of early childhood education. Case teaching can also be combined with role-playing, situational simulation and other methods to increase the sense of presence of theoretical teaching, guide students to learn from the specific cases to summarize the general laws and principles, deepen the understanding of the theory, and improve students' ability to analyze problems and solve problems. At the same time, the evaluation method of the pre-professional training phase is changed. Through the evaluation of the student's learning process and the practice process, the content of the student's practical ability assessment is increased. Through various methods and approaches, students are trained to use theoretical knowledge to deal with problems in the teaching situation. Ability.

Theoretical researchers must not only have the pursuit of educational ideals, but also have concerns about educational practice. They should work more with preschool teachers to study empirical issues and explore effective ways to realize educational ideas. The work of a theoretical researcher should not merely be an elaboration of a conceptual issue, but should also provide specific practical support for preschool teachers, rather than researching practical issues in books. For example, in theory, teachers generally should be used as supporters, helpers, and collaborators of young children. In practice, how teachers should support and assist young children should be in the context of games, teaching, living, and environment creation. How to operate, practice workers need not empty truths, but situational cases and guidance. Therefore, in the theoretical study, the case study is one of the effective links with practice. Of course, the acquisition of a case cannot be merely a book, but more importantly, it can be found from the observation and thinking of a specific situation. 


\section{Conclusion}

Preschool education theory research and preschool education practice should not be mutually exclusive and contradictory. Practitioners should not only be the coordinators of theoretical research, but should be the same researchers as theorists. [9] Only in this way can we achieve a win-win situation in the mutual visits between educational researchers and practitioners.

\section{References}

[1] Pan Yanan. Thinking about the practicality of preschool education and the problems of ancient and modern China and the West[J]. Talents, 2011(22):214.

[2] Jiang Yajun. Three Cognitions and Academic Values in the Research of Preschool Education History[J]. Preschool Education Research,2011(6):31- 33.

[3] Hu Fangfang, Sang Qingsong. The Relationship between the Development of Mental Theories and Family Functions in 3- to 5-year-old Migrant Children[J]. Preschool Education Research,2011(7):42- 48.

[4] Yang Yi, Lan Jijun. Intervention Strategies for the Development of Preschool Children's Theory of Mind[J]. Preschool Education Research,2011(8):44- 48.

[5] Chen Guisheng. Re-recognition of "Relationship between Educational Theory and Practice" [J]. Journal of Educational Science of Hunan Normal University, 2005, (1). 